\title{
Site preference and effect of alloying on elastic properties of ternary B2 NiAl-based alloys
}

\author{
A V Ponomareva, Eyvas Isaev, Yu Kh Vekilov and Igor Abrikosov
}

\section{Linköping University Post Print}

N.B.: When citing this work, cite the original article.

Original Publication:

A V Ponomareva, Eyvas Isaev, Yu Kh Vekilov and Igor Abrikosov, Site preference and effect of alloying on elastic properties of ternary B2 NiAl-based alloys, 2012, Physical Review B. Condensed Matter and Materials Physics, (85), 14, 144117.

http://dx.doi.org/10.1103/PhysRevB.85.144117

Copyright: American Physical Society http://www.aps.org/

Postprint available at: Linköping University Electronic Press http://urn.kb.se/resolve?urn=urn:nbn:se:liu:diva-77535 


\title{
Site preference and effect of alloying on elastic properties of ternary $B 2$ NiAl-based alloys
}

\author{
A. V. Ponomareva, ${ }^{1, *}$ E. I. Isaev, ${ }^{1,2}$ Yu. Kh. Vekilov, ${ }^{1}$ and I. A. Abrikosov ${ }^{2}$ \\ ${ }^{1}$ Theoretical Physics and Quantum Technology Department, National University of Science and Technology MISIS, \\ $R U-119049$ Moscow, Russia \\ ${ }^{2}$ Department of Physics, Chemistry and Biology (IFM), Linköping University, SE-581 83 Linköping, Sweden \\ (Received 14 October 2011; revised manuscript received 18 March 2012; published 25 April 2012)
}

\begin{abstract}
Using the exact muffin-tin orbitals method in conjunction with the coherent potential approximation, we study the site preference of transition metal impurities $\mathrm{X}(\mathrm{X}=\mathrm{Sc}, \mathrm{Ti}, \mathrm{V}, \mathrm{Cr}, \mathrm{W}, \mathrm{Re}, \mathrm{Co})$ in $B 2 \mathrm{NiAl}$ and their effect on its elastic properties. Analyzing interatomic bonding of NiAl-X alloys and elastic characteristics evaluated from the elastic constants $C_{11}, C_{12}$, and $C_{44}$, we predict that the addition of $\mathrm{W}, \mathrm{V}, \mathrm{Ti}$, and Re atoms could yield improved ductility for $B 2 \mathrm{NiAl}-\mathrm{X}$ alloys without significant changes in the macroscopic elastic moduli.
\end{abstract}

DOI: 10.1103/PhysRevB.85.144117

PACS number(s): 75.50.Lk

\section{INTRODUCTION}

The intermetallic compound $B 2 \mathrm{NiAl}$ is widely used in aerospace applications due to its high melting temperature $(T=1911 \mathrm{~K}),{ }^{1}$ good oxidation resistance, and low density. The main problem for application of $\mathrm{NiAl}$ alloys is their low room-temperature ductility. The brittle behavior of these alloys can be managed by various techniques such as microstructural control through processing, fiber strengthening, and second-phase reinforcement, as well as microalloying and macroalloying. ${ }^{2}$ For example, a substantial improvement in ductility has been achieved due to the modification of $\beta$-phase (B2-type) grains by the $\gamma$ phase (A1 type) formed by the addition of $\mathrm{Co}, \mathrm{Fe}$, and $\mathrm{Cr}^{3}$ Studies for fiber-reinforced $\mathrm{NiAl}-\mathrm{X}$ eutectic alloys have shown that NiAl alloyed with the refractory bcc metals $\mathrm{Cr}, \mathrm{Mo}$, and $\mathrm{W}$ possesses promising strength at high temperatures and improved room-temperature ductility. ${ }^{4}$ Ductility enhancement was found in NiAl-Cr(Mo)Hf-Ti alloys, where the disordered bcc (Ti, Hf) solid solution phase together with the Heusler phase $\mathrm{Ni}_{2} \mathrm{Al}$ ( $\mathrm{Ti}, \mathrm{Hf}$ ) precipitation presented at eutectic cell boundaries is responsible for the improved ductility due to the better deformation ability of the (Ti, Hf) solid solution phase. ${ }^{5}$ In the above-mentioned examples the ductility improvement was achieved mainly through the formation of a specific microstructure. Recently the structural, electronic, and elastic properties of $\mathrm{NiAl}$ with $4 d$ alloying elements were studied using the first-principles pseudopotential method ${ }^{6}$ and it was found that Tc, Ru, Rh, and Pd are promising candidates to improve the mechanical properties of NiAl-X alloys.

In this work we study the effect of substitutional alloying on the elastic properties of $B 2 \mathrm{NiAl}$ at the atomic level. We therefore concentrate on the effects characteristic of a solid solution and do not treat explicitly the effect of competing phases and microstructure evolution in alloys. In doing so, we rely on the phenomenological correlation between ductility and certain properties of the solution phases, discussed below. Also, we deal with site preference in NiAl-X alloys. It has been studied earlier by means of experimental ${ }^{7-14}$ and theoretical methods, ${ }^{15-19}$ and the results seem to be controversial. For example, the thermal conductivity measurement suggested that $\mathrm{V}, \mathrm{Nb}, \mathrm{Ta}, \mathrm{Mo}, \mathrm{Fe}, \mathrm{Ru}, \mathrm{Co}$, and Pt atoms preferentially substitute for the $\mathrm{Ni}$ sublattice, but $\mathrm{Cr}$ and $\mathrm{Cu}$ atoms substitute for both $\mathrm{Ni}$ and $\mathrm{Al}$ sites. ${ }^{14}$ At the same time, using atom location by channeling enhanced microanalysis (ALCHEMI), it was found that $\mathrm{V}^{10,11}$ and $\mathrm{Cr}^{12}$ occupy the $\mathrm{Al}$ sublattice, although atom probe field ion microscopy (APFIM) experiments showed that about $70 \%$ of the detected atoms occupy $\mathrm{Al}$ sites. ${ }^{13}$ Results of theoretical studies are also inconsistent regarding some ternary additions. According to Refs. 15, 16, and 18, Cr, V, and Ti substitute for the Al sublattice. However, Hosoda et al. ${ }^{19}$ have shown the possibility for $\mathrm{Cr}, \mathrm{V}$, and Ti to occupy both the Al and the Ni sublattices. More detailed information on experimental and theoretical studies of site preference in NiAl-X alloys is given in Ref. 15.

In the present paper the site occupancy, electronic, and elastic properties of NiAl-X alloys ( $\mathrm{X}=\mathrm{Sc}, \mathrm{Ti}, \mathrm{W}, \mathrm{V}, \mathrm{Cr}, \mathrm{Co}$, $\mathrm{Re}$ ) are studied using the first-principles density functional theory. We calculate the elastic constants $C_{11}, C_{12}$, and $C_{44}$, bulk modulus $B$, Young modulus $E$, and shear modulus $G$ and use the phenomenological Pugh criteria $(G / B \text { ratio })^{20}$ as well as the Cauchy pressure $\left(C_{12}-C_{44}\right)^{21}$ to analyze the brittle vs ductile behavior of solid solutions. Analysis of the density of states (DOS) allows us to establish the direct connection between the changes in interatomic bonding and the elastic properties of alloys.

\section{DETAILS OF THE CALCULATION}

Calculations were performed using the exact muffin-tin orbital (EMTO) method within the coherent potential approximation (CPA). ${ }^{22,23}$ The accuracy of the method was shown to be close to that for full-potential methods. The full charge density $(\mathrm{FCD})^{24}$ was represented by a single-center expansion of the electron wavefunctions in terms of spherical harmonics with orbital moments $l_{\max }^{\mathrm{FCD}}$ up to 8. The EMTO-CPA method has been proven to be highly efficient and accurate enough for calculation of elastic properties of alloys..$^{23,25-29}$ The CPA method was used to simulate substitutionally disordered alloys and the paramagnetic state for NiAl-Cr alloys in the disordered local moments (DLMs) approach, which assumes random collinear orientations of the local magnetic moments. ${ }^{30}$ Selfconsistent electron densities were obtained within the spherical cell approximation and the local density approximation (LDA), and then variational estimates of the total energies were calculated in the generalized gradient approximation (GGA) using the FCD formalism. Integration in the reciprocal space was performed over a grid of $29 \times 29 \times 29 k$ points; 
energy integration was carried out in the complex plane using a semielliptic contour comprising 24 energy points. Calculations were performed for a basis set including valence $s p d f$ orbitals and by means of the soft-core approximation; i.e., the core states were recalculated at each iteration. In our CPA calculations the screening contribution to the electrostatic potential and energy was taken into account in order to describe the charge transfer between the alloy components using screening constants ${ }^{33}$ obtained by the locally self-consistent Greens function method. ${ }^{34}$

Elastic properties of crystals with cubic symmetry are fully characterized by three elastic constants: $C_{11}, C_{12}$, and $C_{44} \cdot{ }^{35}$ The first two constants describe the crystal response to tension, while $C_{44}$ describes the response to shear strain. In order to determine the elastic constants $C^{\prime}=\left(C_{11}-C_{12}\right) / 2$ and $C_{44}$, we applied volume-conserving orthorhombic and monoclinic distortions, respectively, and calculated the internal energy response $^{36}$ to these small distortions. Elastic constants $C_{11}$ and $C_{12}$ can be obtained by the combination of $C^{\prime}$ and bulk modulus $B=\left(C_{11}+2 C_{12}\right) / 3$. The elastic constants derived from the total energy calculations correspond to single-crystal elastic properties. To estimate elastic moduli for polycrystalline materials we used the Voigt-Reuss-Hill approximation. ${ }^{35}$

In order to analyze the brittle vs ductile behavior of solid solutions, we estimated the Pugh ratio $(G / B)^{20}$ and the Cauchy pressure $P_{C}=\left(C_{12}-C_{44}\right),{ }^{21}$ then phenomenologically linked the plastic properties of materials with their elastic properties. According to the Pugh criterion, ${ }^{20}$ a material behaves in a ductile manner if $G / B<0.5$, because in this case the resistance to bond-length change exceeds that to bond-angle change; and vice versa, if $G / B>0.5$, a material demonstrates brittleness. The higher the value of $G / B$, the more brittle the material should be.

Pettifor $^{21}$ suggested that the angular character of atomic bonding in metals and compounds, which can be responsible for the brittle or ductile behavior of materials, might be described by the Cauchy pressure $P_{C}=\left(C_{12}-C_{44}\right)$. The Cauchy relation $C_{12}=C_{44}$ (in the absence of external pressure) is the consequence of centrosymmetric forces, satisfied for inert gas crystals and approximately satisfied for ionic crystals and some metals. This means that interatomic interactions in these crystals could be reasonably described by pair potentials, like Lennard-Jones, the embedded atom potential, etc. Experimentally, in most cases for metals and compounds the Cauchy relation is not obeyed. To capture the correct response of these materials to shear and external pressure, one has to take into account the spatial orientation of bonds via many-body potentials as shown by Brovman and Kagan. ${ }^{37}$ As a result, for covalent materials with a directional character of atomic bonds, the Cauchy pressure is negative $\left(C_{12}<C_{44}\right)$, because in this case the material resistance to the shear strain $\left(C_{44}\right)$ is much more than that for the volume change $\left(C_{12}\right)$. On the other hand, for metallic-like bonding, where electrons are almost delocalized, the Cauchy pressure should be positive $\left(C_{12}>C_{44}\right)$. Another important elastic property is the Zener anisotropy parameter, which is defined as $A_{z}=2 C_{44} /\left(C_{11}-C_{12}\right),{ }^{38}$ showing the difference between the sound velocities for TA1 and TA2 modes traveling along the [110] and [001] directions in the [1 $\overline{10} 0]$ plane. For isotropic crystals $A=1$, while other values are a measure of elastic anisotropy.

\section{RESULTS AND DISCUSSION}

\section{A. Site preference}

First, we determine the site preference of the ternary additions in $B 2 \mathrm{NiAl}$. Following the recipe given in Ref. 39, we calculate the so-called transfer energy $E_{\mathrm{X}}$ :

$$
E_{\mathrm{X}}=\frac{1}{c}\left(E\left(\left(\mathrm{X}_{c} \mathrm{Ni}_{1-c}\right) \mathrm{Al}\right)-E\left(\left(\mathrm{X}_{c} \mathrm{Al}_{1-c}\right) \mathrm{Ni}\right)+E\left(\mathrm{Ni}_{\mathrm{Al}}\right)\right),
$$

where $c$ is the concentration of impurities in the corresponding sublattice. Equation (1) corresponds to the energy needed to move atom $\mathrm{X}$ from the $\mathrm{Ni}$ site to the $\mathrm{Al}$ site. In Eq. (1) $E\left(\left(\mathrm{X}_{c} \mathrm{Ni}_{1-c}\right) \mathrm{Al}\right)$ and $E\left(\left(\mathrm{X}_{c} \mathrm{Al}_{1-c}\right) \mathrm{Ni}\right)$ are energies of substitution alloys with ternary addition $\mathrm{X}$ on the $\mathrm{Ni}$ and $\mathrm{Al}$ sublattices, respectively, and $E\left(\mathrm{Ni}_{\mathrm{Al}}\right)=E\left(\left(\mathrm{Ni}_{c} \mathrm{Al}_{1-c}\right) \mathrm{Ni}\right)-E(\mathrm{NiAl})$ is the energy of the partial antisite defects on the Al sublattice.

If $E_{\mathrm{X}}<0$, then there is a strong $\mathrm{Ni}$ site preference, because atoms $\mathrm{X}$ prefer to go to the $\mathrm{Ni}$ sublattice despite the $\mathrm{Ni}$ antisite formation on the $\mathrm{Al}$ sublattice. ${ }^{40}$ Besides, an atom $\mathrm{X}$ can occupy the $\mathrm{Ni}$ sublattice with the formation of two $\mathrm{Al}$ vacancies $\left(2 \mathrm{~V}_{\mathrm{Al}}\right)$ to keep the $\mathrm{Ni}$ concentration constant. However, as shown in Ref. 40, this configuration is energetically unfavorable because $2 E\left(\mathrm{~V}_{\mathrm{Al}}\right)>E\left(\mathrm{Ni}_{\mathrm{Al}}\right)$. In the case of $E_{\mathrm{X}}>0$ there are two possibilities. First, the $\mathrm{X}$ atom occupies the Al sublattice, with defect formation on the Ni sublattice. In Refs. 40 and 41 it was shown that the dominant thermal defect in stoichiometric $\mathrm{NiAl}$ is a triple $\mathrm{Ni}$ defect, which corresponds to two $\mathrm{Ni}$ vacancies and one antisite $\mathrm{Ni}$ atom on the $\mathrm{Al}$ sublattice $\left(2 \mathrm{~V}_{\mathrm{Ni}}+\mathrm{Ni}_{\mathrm{Al}}\right)$. So, if $E_{\mathrm{X}}>$ $E\left(2 \mathrm{~V}_{\mathrm{Ni}}+\mathrm{Ni}_{\mathrm{Al}}\right)$, then there is a strong $\mathrm{Al}$ preference, because atoms $\mathrm{X}$ always go to the $\mathrm{Al}$ sublattice, even at the cost of creating a triple defect. Second, if $0<E_{\mathrm{X}}<E\left(2 \mathrm{~V}_{\mathrm{Ni}}+\mathrm{Ni}_{\mathrm{Al}}\right)$, then $\mathrm{X}$ atoms do not have any site preference and randomly occupy both $\mathrm{Ni}$ and $\mathrm{Al}$ sublattices. In our calculations we found that the triple defect formation energy $E\left(2 \mathrm{~V}_{\mathrm{Ni}}+\mathrm{Ni}_{\mathrm{Al}}\right)=$ $2.14 \mathrm{eV}$. It is in good agreement with the theoretical result obtained in Ref. 40 (2.37 eV) and with experimental data $(1.90 \mathrm{eV}) .^{42}$

In Table I the calculated transfer energy and the site preferences of some ternary transition-metal additions to $B 2$ NiAl in the dilute limit $(c=1$ at $\%)$ at $T=0 \mathrm{~K}$ are presented.

TABLE I. Transfer energy and site preference of some ternary additions in $B 2 \mathrm{NiAl}$ obtained in the dilute limit and at $T=0 \mathrm{~K}$. The calculated formation energy of the triple defect is $E\left(2 \mathrm{~V}_{\mathrm{Ni}}+\mathrm{Ni}_{\mathrm{Al}}\right)=$ $2.14 \mathrm{eV}$

\begin{tabular}{lcc}
\hline \hline Element & Transfer energy $(\mathrm{eV})$ & Site preference \\
\hline $\mathrm{Sc}$ & 3.00 & $\mathrm{Al}$ \\
$\mathrm{Ti}$ & 2.92 & $\mathrm{Al}$ \\
$\mathrm{V}$ & $1.95 \mathrm{~d}$ & $\mathrm{Ni}, \mathrm{Al}$ \\
$\mathrm{Cr}(\mathrm{DLM})$ & 1.41 & $\mathrm{Ni}, \mathrm{Al}$ \\
$\mathrm{W}$ & 0.90 & $\mathrm{Ni}, \mathrm{Al}$ \\
$\mathrm{Co}$ & -0.28 & $\mathrm{Ni}$ \\
$\mathrm{Re}$ & -0.39 & $\mathrm{Ni}$ \\
\hline \hline
\end{tabular}


TABLE II. Calculated lattice parameters $(a)$, elastic constants $\left(C_{11}, C_{12}, C_{44}\right)$, bulk moduli $(B)$, Young moduli $(E)$, and shear moduli $(G)$ of $B 2 \mathrm{NiAl}$ compared with previous calculations and available experimental measurements.

\begin{tabular}{|c|c|c|c|c|c|c|c|c|}
\hline Ref. No. & Method(s) & $\begin{array}{c}a \\
(\AA)\end{array}$ & $\begin{array}{c}C_{11} \\
(\mathrm{GPa})\end{array}$ & $\begin{array}{c}C_{12} \\
(\mathrm{GPa})\end{array}$ & $\begin{array}{c}C_{44} \\
(\mathrm{GPa})\end{array}$ & $\begin{array}{c}B \\
(\mathrm{GPa})\end{array}$ & $\begin{array}{c}E \\
(\mathrm{GPa})\end{array}$ & $\begin{array}{c}G \\
(\mathrm{GPa})\end{array}$ \\
\hline Our results & EMTO & 2.89 & 233 & 121 & 114 & 159 & 218 & 85 \\
\hline 27 & EMTO & 2.89 & 232 & 121 & 111 & 158 & 214 & 84 \\
\hline 46 & LAPW, LDA, $a_{\text {equilibrium }}$ & 2.84 & 237 & 155 & 132 & & 186 & \\
\hline 46 & LAPW, LDA, $a_{\text {experimental }}$ & 2.89 & 193 & 124 & 114 & 147 & 184 & 71 \\
\hline 47 & LAWP, LDA & 2.84 & 262 & 146 & 138 & 185 & & \\
\hline 48 & CASTEP GGA & 2.90 & 161 & 150 & 117 & 153 & 180 & 70 \\
\hline 49 & FLAPW LDA & 2.82 & 236 & 167 & 140 & 187 & & \\
\hline 49 & FLAPW GGA & 2.89 & 189 & 131 & 107 & 150 & & \\
\hline 50 & VASP PAW GGA, $T=0 \mathrm{~K}$ & & 200 & 125 & 112 & & & \\
\hline 51 & VASP ultrasoft LDA & 2.84 & 218 & 153 & 128 & & & \\
\hline 52 & VASP PAW GGA & 2.89 & 203 & 140 & 113 & & & \\
\hline 53 & $\begin{array}{l}\text { Elastic constants were determined by the slopes } \\
\text { of measured acoustic phonon frequencies at } 296 \mathrm{~K}\end{array}$ & & 197 & 119 & 110 & 145 & & \\
\hline 54 & Expt. & 2.89 & 212 & 143 & 112 & 166 & 184 & 70 \\
\hline 55 & Expt., ultrasonic pulse-echo method at $298 \mathrm{~K}$ & & 199 & 137 & 116 & 158 & & \\
\hline 56 & Expt., ultrasonic pulse-echo method at $295 \mathrm{~K}$ & & 205 & 135 & 117 & 159 & & \\
\hline
\end{tabular}

One can see that some substitutional metals $\mathrm{X}$ have a strong preference for either the $\mathrm{Al}$ or the $\mathrm{Ni}$ sublattice in $B 2 \mathrm{NiAl}$, but some of them do not have any particular site preference (i.e., atom $\mathrm{X}$ can substitute randomly the $\mathrm{Al}$ or the Ni sublattice). The early transition metals Sc and Ti are found to substitute preferentially $\mathrm{Al}$, whereas Re and $\mathrm{Co}$ are found to have a strong preference for the Ni sublattice. $\mathrm{Cr}, \mathrm{W}$, and $\mathrm{V}$ are predicted to have no site preference. The results are in agreement with the site preference of $3 d, 4 d$, and $5 d$ transition metals in $\mathrm{NiAl}$ previously studied in Ref. 43 by the Vienna $A b$ Initio Simulation Package (VASP). ${ }^{44,45}$ The latter allows one to consider the effect of local atomic relaxations. Good agreement between the two calculations demonstrates that their neglect in our calculations does not introduce significant inaccuracy for systems considered in this study.

The site preference behavior reported in Table I is valid in the dilute limit and at $T=0 \mathrm{~K}$. As demonstrated in Ref. 39, it is possible for the site preference to be changed at a high temperature and concentration. Indeed, as shown in Ref. 43 using the Wagner-Schottky model, in stoichiometric NiAl, elements with no site preference randomly distributed between $\mathrm{Al}$ and $\mathrm{Ni}$ sites at low temperatures ( $\mathrm{V}, \mathrm{W}, \mathrm{Cr}$ atoms) start to exhibit a preference for the $\mathrm{Al}$ sublattice at higher temperatures. The ground-state configuration at nonzero temperatures

TABLE III. Calculated lattice parameters $(a)$, elastic constants $\left(C_{11}, C_{12}, C_{44}\right)$, bulk moduli $(B)$, Young moduli $(E)$, shear moduli $(G)$, and Zener anisotropy parameters $\left(A_{z}\right)$ of NiAl-based alloys. For NiAl-Cr alloys we consider only the paramagnetic state in the disordered local moments approach.

\begin{tabular}{|c|c|c|c|c|c|c|c|c|}
\hline & $a(\AA)$ & $C_{11}(\mathrm{GPa})$ & $C_{12}(\mathrm{GPa})$ & $C_{44}(\mathrm{GPa})$ & $B(\mathrm{GPa})$ & $E(\mathrm{GPa})$ & $G(\mathrm{GPa})$ & $A_{z}$ \\
\hline $\mathrm{NiAl}$ & 2.89 & 233 & 121 & 114 & 159 & 218 & 85 & 2.1 \\
\hline$\left(\mathrm{Re}_{10} \mathrm{Ni}_{90}\right) \mathrm{Al}$ & 2.92 & 230 & 124 & 121 & 159 & 220 & 87 & 2.3 \\
\hline$\left(\mathrm{Re}_{50} \mathrm{Ni}_{50}\right) \mathrm{Al}$ & 3.00 & 232 & 154 & 138 & 180 & 216 & 83 & 3.5 \\
\hline$\left(\mathrm{W}_{05} \mathrm{Al}_{95}\right)\left(\mathrm{W}_{05} \mathrm{Ni}_{95}\right)$ & 2.92 & 234 & 132 & 117 & 166 & 215 & 84 & 2.3 \\
\hline$\left(\mathrm{W}_{25} \mathrm{Al}_{75}\right)\left(\mathrm{W}_{25} \mathrm{Ni}_{75}\right)$ & 3.00 & 241 & 154 & 128 & 183 & 217 & 83 & 3.0 \\
\hline$\left(\mathrm{V}_{05} \mathrm{Al}_{95}\right)\left(\mathrm{V}_{05} \mathrm{Ni}_{95}\right)$ & 2.91 & 223 & 125 & 113 & 158 & 207 & 81 & 2.3 \\
\hline$\left(\mathrm{V}_{10} \mathrm{Al}_{90}\right)\left(\mathrm{V}_{10} \mathrm{Al}_{90}\right)$ & 2.92 & 218 & 128 & 112 & 158 & 200 & 77 & 2.5 \\
\hline$\left(\mathrm{Ti}_{10} \mathrm{Al}_{90}\right) \mathrm{Ni}$ & 2.91 & 234 & 121 & 110 & 159 & 214 & 84 & 1.9 \\
\hline$\left(\mathrm{Ti}_{50} \mathrm{Al}_{50}\right) \mathrm{Ni}$ & 2.96 & 223 & 126 & 88 & 159 & 182 & 70 & 1.8 \\
\hline$\left(\mathrm{Sc}_{10} \mathrm{Al}_{90}\right) \mathrm{Ni}$ & 2.93 & 224 & 114 & 103 & 150 & 203 & 80 & 1.9 \\
\hline$\left(\mathrm{Sc}_{50} \mathrm{Al}_{50}\right) \mathrm{Ni}$ & 3.04 & 196 & 94 & 71 & 128 & 160 & 64 & 1.4 \\
\hline$\left(\mathrm{Co}_{10} \mathrm{Ni}_{90}\right) \mathrm{Al}$ & 2.89 & 235 & 123 & 117 & 161 & 221 & 87 & 2.1 \\
\hline$\left(\mathrm{Co}_{80} \mathrm{Ni}_{20}\right) \mathrm{Al}$ & 2.86 & 268 & 127 & 135 & 174 & 260 & 104 & 2.1 \\
\hline$\left(\mathrm{Cr}_{05} \mathrm{Al}_{95}\right)\left(\mathrm{Cr}_{05} \mathrm{Ni}_{95}\right)$ & 2.90 & 224 & 122 & 115 & 156 & 212 & 83 & 2.2 \\
\hline$\left(\mathrm{Cr}_{15} \mathrm{Al}_{85}\right)\left(\mathrm{Cr}_{15} \mathrm{Ni}_{85}\right)$ & 2.91 & 213 & 119 & 116 & 151 & 210 & 81 & 2.5 \\
\hline$\left(\mathrm{Cr}_{50} \mathrm{Ni}_{50}\right) \mathrm{Al}$ & 2.96 & 189 & 108 & 120 & 135 & 196 & 78 & 3.0 \\
\hline$\left(\mathrm{Cr}_{50} \mathrm{Al}_{50}\right) \mathrm{Ni}$ & 2.90 & 195 & 138 & 120 & 157 & 178 & 68 & 4.2 \\
\hline
\end{tabular}


and nondilute concentrations can be obtained using more sophisticated computer simulation methods, for example, Monte Carlo simulations.

Our results are in good agreement with available experimental data. Using the extended $\mathrm{x}$-ray absorption fine-structure spectroscopy (EXAFS) technique, ${ }^{7}$ it was found that $\mathrm{Co}$ predominantly occupies the $\mathrm{Ni}$ sites in $\mathrm{B} 2 \mathrm{NiAl}$, and by means of atom probe field ion microscopy (APFIM) ${ }^{8}$ it was found that $\mathrm{Re}$ has a strong preference for the Ni sublattice in NiAl. Using atom location by channeling enhanced microanalysis (ALCHEMI) for $\mathrm{Ti}^{9}$ and $\mathrm{V},{ }^{10,11}$ it was detected that these elements exhibit a strong preference for the Al sublattice. Although $\mathrm{V}$ in our calculation has no site preference, the experimental results can be explained by the fact that it can change site preference at high temperatures as shown in Ref. 43.

\section{B. Elastic properties}

In order to analyze the alloying effect of some $3 d$ and $5 d$ metals on the elastic properties of $B 2 \mathrm{NiAl}$, the lattice parameters, elastic constants $C_{11}, C_{12}$, and $C_{44}$, Young modulus $E$, bulk modulus $B$, and shear modulus $G$ of the studied materials were calculated. To verify the accuracy of our calculations, we first compare the calculated results of these properties for ordered $\mathrm{NiAl}$ with theoretical and experimental data from the literature $27,46-56$ (Table II). In general, our results are in good agreement with experiments and previous theoretical calculations. Our results for $C_{11}$ are closer to the upper bound of the available theoretical estimations, while for $C_{12}$ and $C_{44}$ we are closer to the lower bound. We note that there is a certain spread in the calculated elastic constants obtained by different groups, even when the same methodology is used..$^{50,52}$ Thus, it is difficult to identify a particular reason for the deviations between different calculations. In comparison with experiment, an excellent correlation between our theoretical and the experimental lattice parameter, bulk modulus, and elastic constant $C_{44}$ is found. The $C_{11}$ obtained in our calculation is slightly higher than the experimental values and the $C_{12}$ is slightly lower than most of the experimental results (Table II). Therefore, the Pugh ratio $(G / B)$ is somewhat overestimated in comparison with the experimental data for $B 2 \mathrm{NiAl}$, while the Cauchy pressure is underestimated. Thus in our calculations NiAl turns out to be "more brittle" than it actually is. Still, within the accuracy offered by the phenomenological criterion of brittle vs ductile behavior, we can analyze qualitatively trends upon alloying, which is the task of our study.

Selected results for studied alloys are summarized in Table III and the complete database is shown in the Appendix. We find that for NiAl-X alloys at a low $\mathrm{X}$ concentration the well-known criteria for mechanical stability of cubic crystals $\left(C_{11}-C_{12}\right)>0$ and $C_{44}>0$ are fulfilled if ternary additions

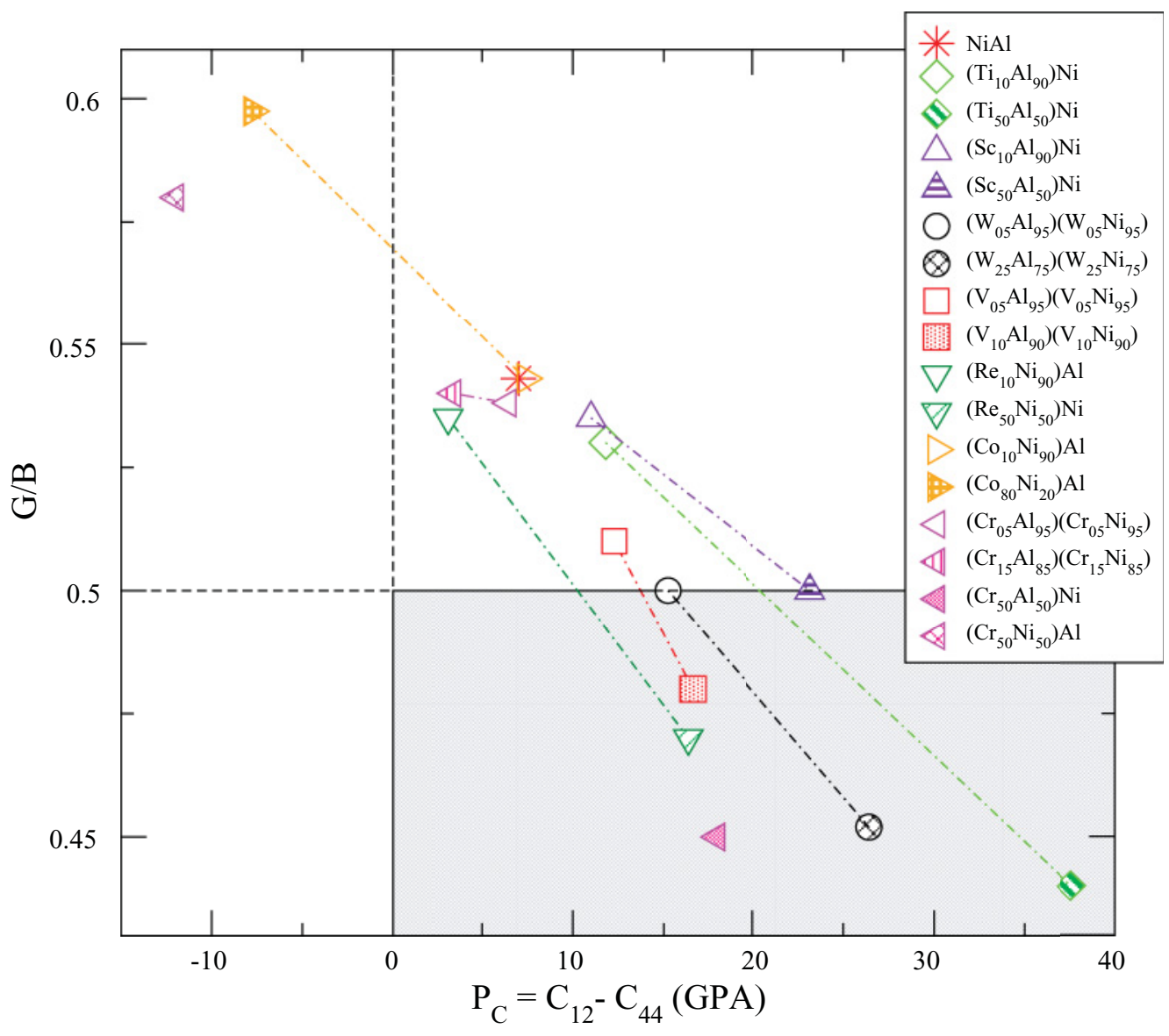

FIG. 1. (Color online) Calculated map of brittle/ductile transition for NiAl-X alloys. The shaded area indicates more ductile behavior according to both the Pugh ratio $G / B$ and the Cauchy pressure $P_{C}=\left(C_{12}-C_{44}\right)$ criteria. 


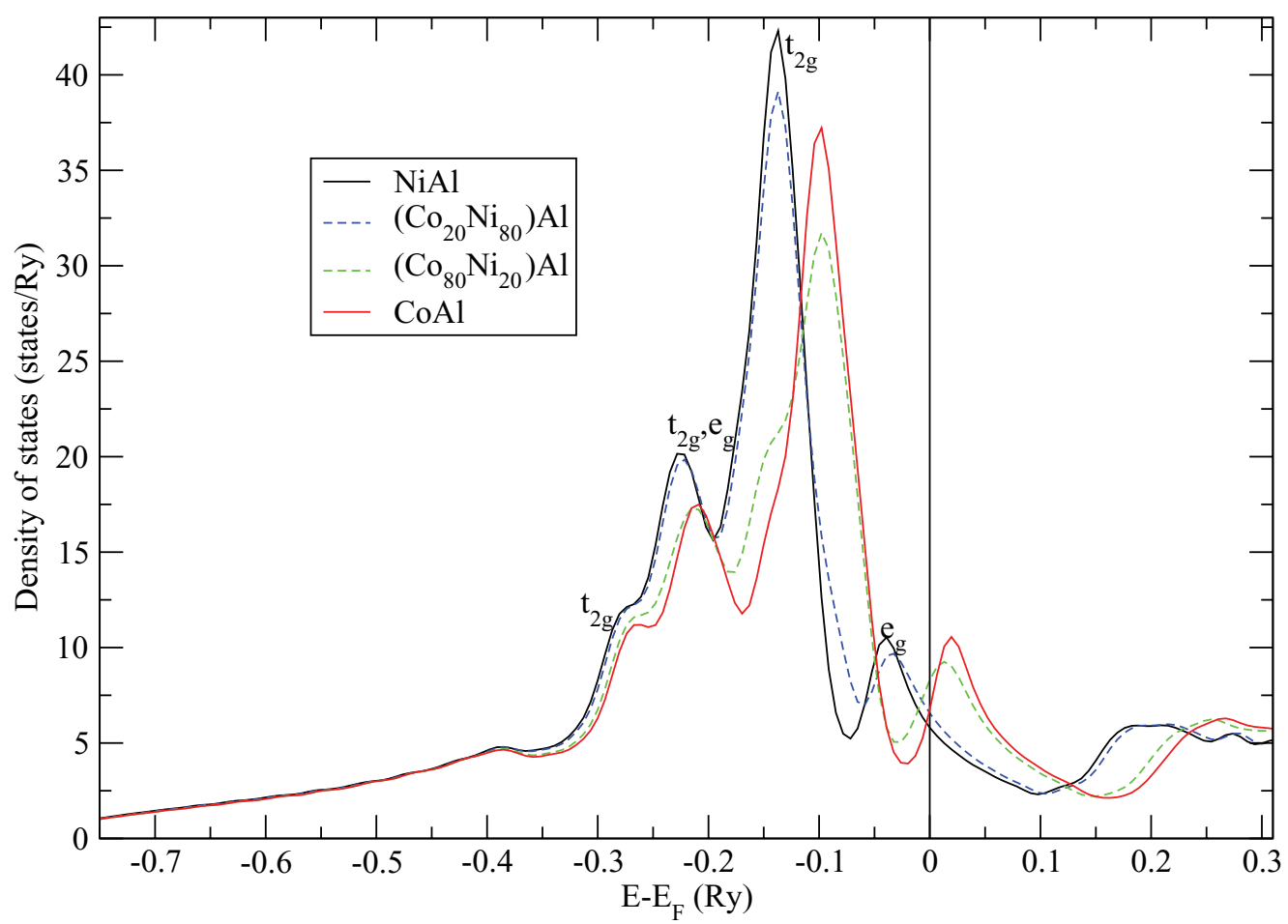

FIG. 2. (Color online) Total density of states for $\mathrm{NiAl}, \mathrm{CoAl}$, and $\left(\mathrm{Co}_{c} \mathrm{Ni}_{1-c}\right) \mathrm{Al}$ alloys calculated by means of the EMTO-CPA method. The Fermi level is set to 0 .

are located in their preferred sites. Let us note that for the studied NiAl-X alloys, $B>G>C^{\prime}$, indicating that the shear modulus $C^{\prime}$ is the limiting parameter for the mechanical stability of the alloys.

In Fig. 1 we present the phenomenological estimation of brittle vs ductile behavior of ternary NiAl-X alloys. Following Ref. 57, we plot the Pugh ratio $G / B$ versus the Cauchy pressure. To understand the composition effect on the elastic properties and ductility, we show the results in the dilute limit (total concentration of ternary additions $\mathrm{X}$ is 5 at\%) and at a few nondilute concentrations of alloys under the assumption that the ternary additions still occupy the positions following the site preference trend summarized in Table I. Note, however, that in principle, the site preference of particular ternary additions can be changed with increased concentration and temperature as mentioned above. ${ }^{39}$

First, we consider alloying of $B 2 \mathrm{NiAl}$ with Co. In this case we examined the elastic properties in the whole concentration range $c=0-100$ at $\%$ because the type of interatomic interaction changes drastically with increasing Co concentration (see Fig. 4). The $G / B$ ratio and Cauchy pressure $P_{C}$ for NiAl-Co alloys change their values only slightly with Co concentration up to 50 at $\%$, but in the concentration range $50-100$ at $\%$ the ratio $G / B$ increases sharply while $P_{C}$ decreases and then becomes negative (Fig. 4). This indicates a change in the bonding character and an increase in the brittleness of the $\left(\mathrm{Co}_{c} \mathrm{Ni}_{1-c}\right) \mathrm{Al}$ alloys. Note that the negative Cauchy pressure for $B 2 \mathrm{CoAl}$ was confirmed experimentally. ${ }^{58} \mathrm{At}$ a Co concentration of less than $50 \% C_{11}$ and $C_{12}$ increase slightly; at a higher Co concentration $C_{11}$ increases dramatically, while $C_{12}$ is considerably reduced. $C_{44}$ increases monotonically over the whole concentration range. As a result, the shear modulus $G$ and Young modulus $E$ are enhanced. Note that $B$ increases by only $12 \%$, while $E$ and $G$ increase much more, by up to $30 \%$.

In order to understand the reason for the changes of bonding character in the (Co-Ni)Al system, we analyzed the variation of the electronic DOS with increasing Co concentration in terms of the tight-binding model ${ }^{59}$ (Fig. 2). For the $B 2 \mathrm{NiAl}$ phase the main contribution to the DOS around $E_{f}$ comes from narrow $d$ bands of Ni. These bands form a pseudogap in the DOS between the so-called nonbonding, ${ }^{60}$ predominantly $t_{2 g}$ states (from -0.25 to $-0.1 \mathrm{Ry}$ ) with a small contribution from $e_{g}$ states (from -0.25 to $-0.2 \mathrm{Ry}$ ) and the antibonding $e_{g}$ states right below the Fermi energy $E_{F}$. As a Co atom has one less valence electron than $\mathrm{Ni}$, the Fermi level shifts toward a lower energy with increasing Co concentration, in agreement with what can be expected from the rigid bands model. Thus, as one can see from Fig. 2, in the case of pure $B 2 \mathrm{NiAl}$ both $t_{2 g}$ and $e_{g}$ states are filled, whereas in CoAl the antibonding $e_{g}$ states remain almost empty. The $t_{2 g}\left(d_{x y}, d_{y z}, d_{z x}\right)$ electrons are directed toward the eight nearest-neighbor atoms in the bcc lattice, e.g., in our case, toward $\mathrm{Al}$ and $\mathrm{Ni}$ or $\mathrm{Al}$ and $\mathrm{Co}$ atoms, located on different sublattices of the $B 2$ unit cell. The $e_{g}$ $\left(d_{x^{2}-y^{2}}\right.$ and $d_{z^{2}}$ ) electrons are directed toward the next-nearestneighbor atoms located on the same sublattice. For NiAl, $t_{2 g}$ and $e_{g}$ states are almost fully occupied, and therefore there should be no specific direction in the electron charge density distribution. On the other hand, in $B 2 \mathrm{CoAl}$ the $t_{2 g}$ states are fully occupied while the $e_{g}$ states are mostly located above the Fermi level. This promotes more directional electron charge density distribution toward the nearest neighbors. As a result, 


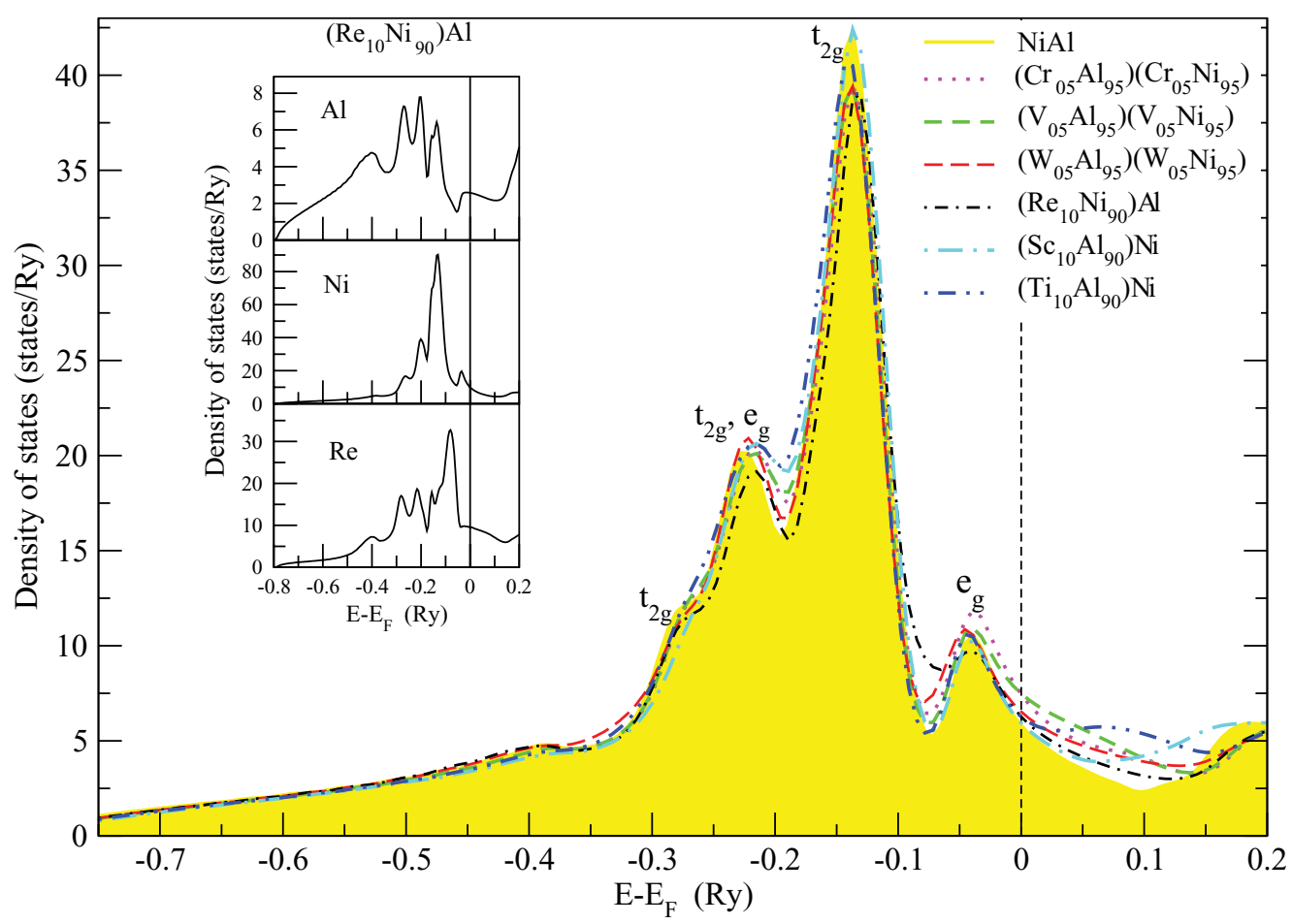

FIG. 3. (Color online) Calculated total density of states for NiAl containing $\mathrm{Cr}, \mathrm{V}, \mathrm{W}, \mathrm{Re}, \mathrm{Sc}$, and Ti located on different sublattices of the $B 2$ structure. Inset: Calculated atom-projected densities of electron states in $B 2\left(\mathrm{Re}_{10} \mathrm{Ni}_{90}\right) \mathrm{Al}$ alloy. The Fermi level is set to 0.

the character of bonding in these two intermetallics should be different: in $\mathrm{NiAl}$ metallic bonding is predominant (though covalent and ionic bonding are also present), while in CoAl the covalent type of bonding increases. The covalent component is responsible for more brittle behavior in Co-rich $\left(\mathrm{Co}_{c} \mathrm{Ni}_{1-c}\right)$ $\mathrm{Al}$ alloys. A trend in the lattice constant dependence, i.e., its increase from $\mathrm{CoAl}$ to $\mathrm{NiAl}$, is also consistent with the filling of the antibonding $e_{g}$ states. The decrease in the lattice parameter in NiAl-Co alloys with increasing Co content also causes an enhancement of the elastic constant $C_{11}$, as a shorter distance provides a larger overlap between Co $d$ states on next-nearest-neighbor Co atoms.

Let us return to the discussion of Fig. 1. For $\left(\mathrm{W}_{c} \mathrm{Ni}_{(1-c)}\right)\left(\mathrm{W}_{c} \mathrm{Al}_{(1-c)}\right)$ and $\left(\mathrm{V}_{c} \mathrm{Ni}_{(1-c)}\right)\left(\mathrm{V}_{c} \mathrm{Al}_{(1-c)}\right)$ alloys for the given concentration (Table III) and for $\left(\mathrm{Re}_{c} \mathrm{Ni}_{1-c}\right) \mathrm{Al}$ for $c>10$ at $\%$, both the Pugh ratio and the Cauchy pressure predict an improved ductility. For NiAl-Re and NiAl-W alloys the elastic modulus $C_{11}$ is almost constant at low concentrations of $\mathrm{Re}$ and $\mathrm{W}$, while $C_{12}$ and $C_{44}$ increase monotonically, despite the fact that $C_{44}$ usually decreases with increasing ductility, as is the case in $\left(\mathrm{V}_{c} \mathrm{Ni}_{(1-c)}\right)\left(\mathrm{V}_{c} \mathrm{Al}_{(1-c)}\right)$ alloys (see the Appendix). This suggests that alloying of NiAl with Re or $\mathrm{W}$ enhances both metallic and covalent types of interactions: although bonds are mainly metallic $\left(C_{12}>\right.$ $C_{44}$ ), increased $C_{44}$ indicates an enhanced partial covalent component of the bonding.

Figure 3 shows the calculated DOS for NiAl-X alloys with $\mathrm{X}=\mathrm{Cr}, \mathrm{V}, \mathrm{W}, \mathrm{Re}, \mathrm{Sc}$, and Ti. One can see that for NiAl-Re $t_{2 g}$ nonbonding and for NiAl-W alloys $e_{g}$ antibonding peaks are smeared out and broadened. This delocalization of $t_{2 g}$ and $e_{g}$ electrons provides an enhanced metallic component to the bonding. The substitution of $\mathrm{Ni}$ with $\mathrm{Re}(\mathrm{W})$ increases the hybridization between $\mathrm{Al} p$ and $\operatorname{Re}(\mathrm{W}) d$ states with $t_{2 g}$ symmetry due to the weaker spatial localization of $5 d$ electrons of Re and W compared with $3 d$ electrons of $\mathrm{Ni}$ [see the inset in Fig. 3, where the atom-projected DOS for the $B 2\left(\mathrm{Re}_{10} \mathrm{Ni}_{90}\right) \mathrm{Al}$ alloy is shown]. This increases the covalent component of bonding and enhances the shear resistance. For $\left(\mathrm{V}_{c} \mathrm{Ni}_{(1-c)}\right)\left(\mathrm{V}_{c} \mathrm{Al}_{(1-c)}\right)$ alloys the metallic bonding remains predominant, mainly owing to the contribution of $e_{g}$ electrons of $\mathrm{V}$ to the antibonding peak (Fig. 3).

In the case of paramagnetic (DLM) $\left(\mathrm{Cr}_{c} \mathrm{Ni}_{(1-c)}\right)\left(\mathrm{Cr}_{c} \mathrm{Al}_{(1-c)}\right)$ alloys, changes in the parameter $G / B$ and the Cauchy pressure are small, and the decrease in $C_{11}$ is more pronounced compared to other moduli. Note that if $\mathrm{Cr}$ atoms are located only on the Ni sublattice, the Cauchy pressure becomes negative with increasing $\mathrm{Cr}$ concentration, as takes place for Co (Fig. 1). If $\mathrm{Cr}$ atoms are placed on the $\mathrm{Al}$ sublattice, as suggested in some experimental ${ }^{12,13}$ and theoretical studies, ${ }^{15,16,18}$ the Cauchy pressure is positive and increases (Fig. 1). The metallic component of the bonding formed in these alloys is due to $\mathrm{Cr}$ $\mathrm{Ni}$ interactions, while the covalent component is formed by the interaction of $\mathrm{Cr}$ and $\mathrm{Al}$ atoms. But in $\left(\mathrm{Cr}_{c} \mathrm{Ni}_{(1-c)}\right)\left(\mathrm{Cr}_{c} \mathrm{Al}_{(1-c)}\right)$ alloys where $\mathrm{Cr}$ atoms occupy both $\mathrm{Ni}$ and $\mathrm{Al}$ sublattices with equal probability, interatomic interactions on different sublattices have the opposite effect on the elastic properties, and as a result, the brittle vs ductile behavior is affected only slightly (see Fig. 6).

In $\left(\mathrm{Ti}_{c} \mathrm{Al}_{1-c}\right) \mathrm{Ni}$ alloys elastic constants $C_{11}$ and $C_{44}$ decrease with increasing Ti concentration. At the same time, $C_{12}$ increases slightly, and the decrease in $C_{44}$ is more pronounced compared to $C_{11}$ (see Fig. 5). This leads to a 

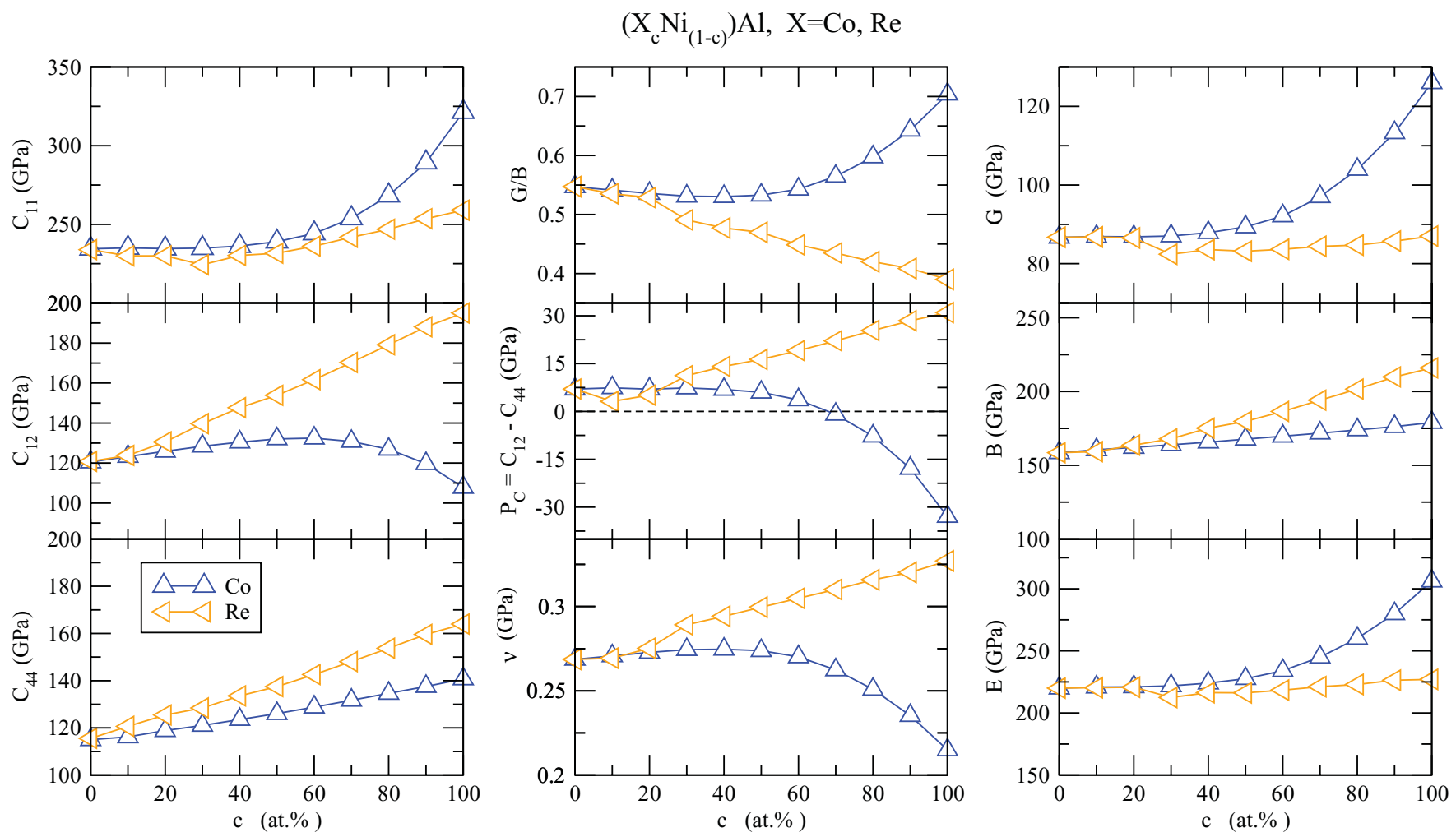

FIG. 4. (Color online) Calculated elastic constants $C_{11}, C_{12}$, and $C_{44}$, Pugh ratio $G / B$, Cauchy pressure $P_{C}=\left(C_{12}-C_{44}\right)$, Poisson ratio $v$, shear moduli $G$, bulk moduli $B$, and Young moduli $E$ of NiAl-X alloys with $\mathrm{X}=\mathrm{Co}$ and Re located on the Ni sublattice.

decrease in the shear moduli $C^{\prime}, G$, and the Young modulus $E$. The bulk modulus $B$ is almost constant while the lattice parameter increases, meaning that the average valence electron density is not increased, despite the partial substitution of $\mathrm{Al}$ with $\mathrm{Ti}$ and the increased number of valence electrons. In comparison with $\mathrm{NiAl}$ the $G / B$ ratio decreases; at the same the Cauchy pressure becomes more positive with increasing $\mathrm{Ti}$ concentration. This indicates a reduction in the covalent contribution to the bonding.

Similar behavior of elastic constants is observed in the case of alloying of $\mathrm{NiAl}$ with $\mathrm{Sc}$, where there is a strong decrease in $C_{11}, C_{44}, G$, and $E$ (up to 60 at\% Sc). In addition, the bulk modulus $B$ and $C_{12}$ are also reduced. In $\left(\mathrm{Sc}_{c} \mathrm{Al}_{1-c}\right) \mathrm{Ni}$ alloys we find a reduced covalent contribution to the interatomic bonds, as follows from the decreases in the $G / B$ ratio and increases in the Cauchy pressure. Nevertheless, in this case changes in $G / B$ and Cauchy pressure are not as significant as for $\left(\mathrm{Ti}_{c} \mathrm{Al}_{1-c}\right) \mathrm{Ni}$ alloys. This might be due to the fact that in $\left(\mathrm{Sc}_{c} \mathrm{Al}_{1-c}\right) \mathrm{Ni}$ alloys there is a stronger contribution of the ionic component to interatomic interaction, in addition to mainly metallic bonding. The charge transfer caused by the difference in electronegativities might lead to an ionic admixture to the bonding. For Sc, which has the largest difference in electronegativities from $\mathrm{Ni}$ of all studied ternary additions, we found the lowest Zener anisotropy parameter $A_{z}$ (Table III), indicating more isotropic behavior of NiAl-Sc alloys.

Alloying of $\mathrm{NiAl}$ with $\mathrm{Ti}$ and $\mathrm{Sc}$ smears out the nonbonding peak of the DOS. The pseudogap located at $-0.2 \mathrm{Ry}$ is due to $d$ electrons of $\mathrm{Ti}(\mathrm{Sc})$. There is significant charge transfer from $t_{2 g}$ states of $\mathrm{Ti}(\mathrm{Sc})$ to $e_{g}$ states of $\mathrm{Ni}$. At the same time, antibonding states near the Fermi energy remain almost unchanged (Fig. 3).

\section{CONCLUSION}

In this work we have carried out a systematic theoretical study of the influence of alloying on the elastic properties of $B 2 \mathrm{NiAl}$. First, we investigated the site preference of ternary additions at $T=0 \mathrm{~K}$ and observed that the early transition metals $\mathrm{Sc}$ and $\mathrm{Ti}$ preferentially substitute for $\mathrm{Al}$, whereas $\mathrm{Re}$ and $\mathrm{Co}$ have a strong preference for the $\mathrm{Ni}$ sublattice. $\mathrm{Cr}, \mathrm{W}$, and $\mathrm{V}$ are predicted to have no site preference. Considering these impurities at their preferential sites, we created a database of ab initio elastic constants $C_{11}, C_{12}$, and $C_{44}$, shear moduli $G$, bulk moduli $B$, Young moduli $E$, Pugh ratio $G / B$, and Cauchy pressure $P_{C}$. The database was then used to analyze the mechanical behavior of the alloys using phenomenological correlations between ductility and elastic properties of solution phases. Our calculations have shown that the addition of $\mathrm{W}, \mathrm{V}, \mathrm{Re}$, and Ti should improve the ductility of $B 2 \mathrm{NiAl}$ without significant changes in the macroscopic elastic moduli (at a low concentration of $\mathrm{W}$, $\mathrm{V}$, and Ti). For these metals the main contribution to the bonding in the alloys has a metallic character. Changes in bonding of the $\left(\mathrm{Ti}_{c} \mathrm{Al}_{1-c}\right) \mathrm{Ni}$ and $\left(\mathrm{V}_{c} \mathrm{Ni}_{(1-c)}\right)\left(\mathrm{V}_{c} \mathrm{Al}_{(1-c)}\right)$ alloys, in comparison with $\mathrm{NiAl}$, are mainly due to the delocalization of $d$ electrons occupying antibonding states. The $\left(\operatorname{Re}_{c} \mathrm{Ni}_{1-c}\right) \mathrm{Al}$ and $\left(\mathrm{W}_{c} \mathrm{Ni}_{(1-c)}\right)\left(\mathrm{W}_{c} \mathrm{Al}_{(1-c)}\right)$ alloys also contain a directional covalent bonding contribution. $\mathrm{Co}, \mathrm{Sc}$, and $\mathrm{Cr}$ should not 
$\left(\mathrm{X}_{\mathrm{c}} \mathrm{Ni}_{(1-\mathrm{c})}\right) \mathrm{Al}, \mathrm{X}=\mathrm{Ti}, \mathrm{Sc}$
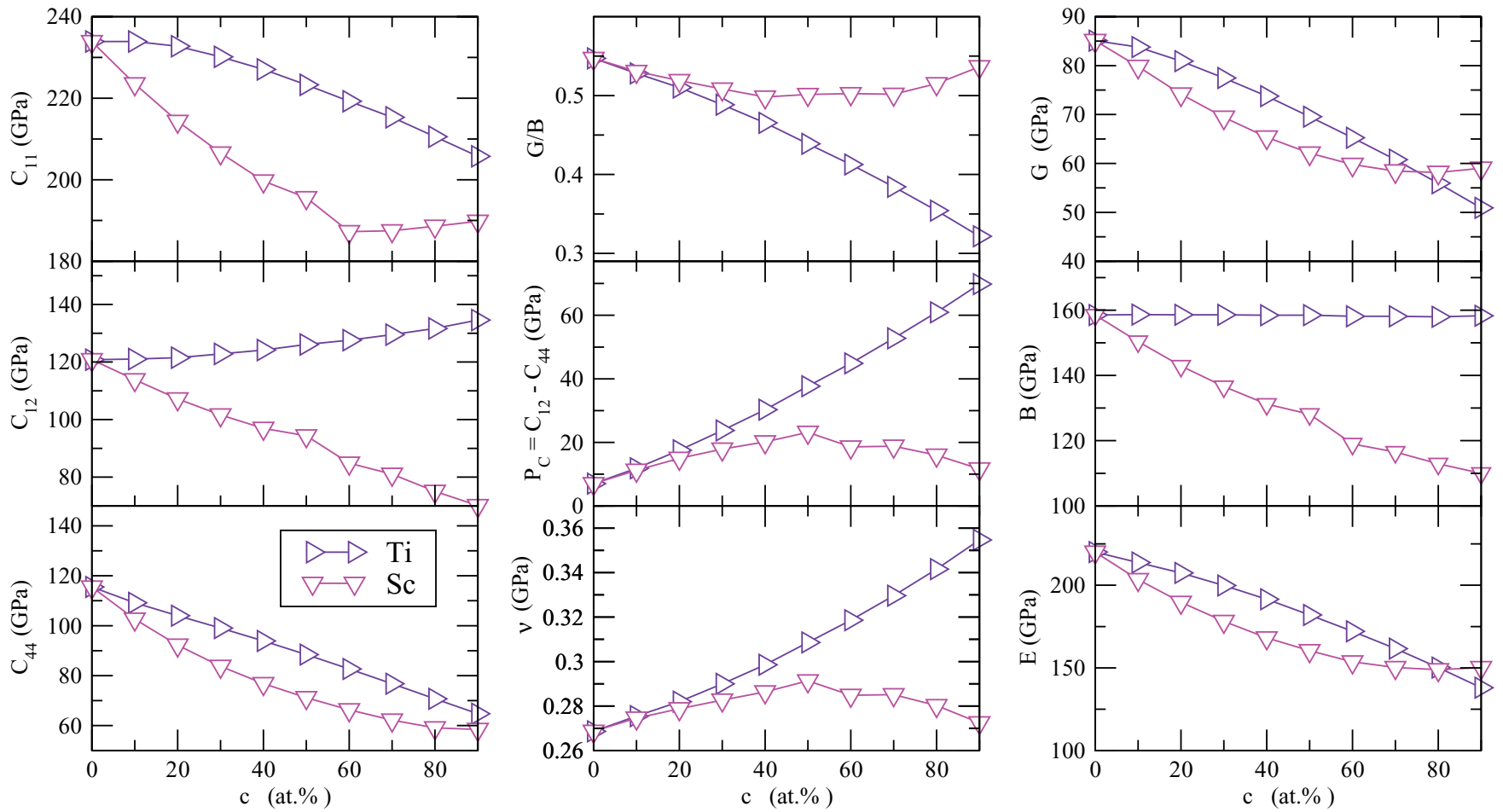

FIG. 5. (Color online) Calculated elastic constants $C_{11}, C_{12}$ and, $C_{44}$, Pugh ratio $G / B$, Cauchy pressure $P_{C}=\left(C_{12}-C_{44}\right)$, Poisson ratio $v$, shear moduli $G$, bulk moduli $B$, and Young moduli $E$ of NiAl-X alloys with $\mathrm{X}=\mathrm{Sc}$ and Ti located on the Al sublattice.

lead to improvements in the ductility of $B 2 \mathrm{NiAl}$. In Co$\mathrm{NiAl}$ alloys the type of interatomic interactions changes from predominantly metallic to covalent with increasing Co concentration. The NiAl-Sc alloys are more isotropic than $B 2 \mathrm{NiAl}$ due to the significant ionic component in addition to metallic bonding. $\mathrm{Cr}$ addition (located on both $\mathrm{Ni}$ and $\mathrm{Al}$
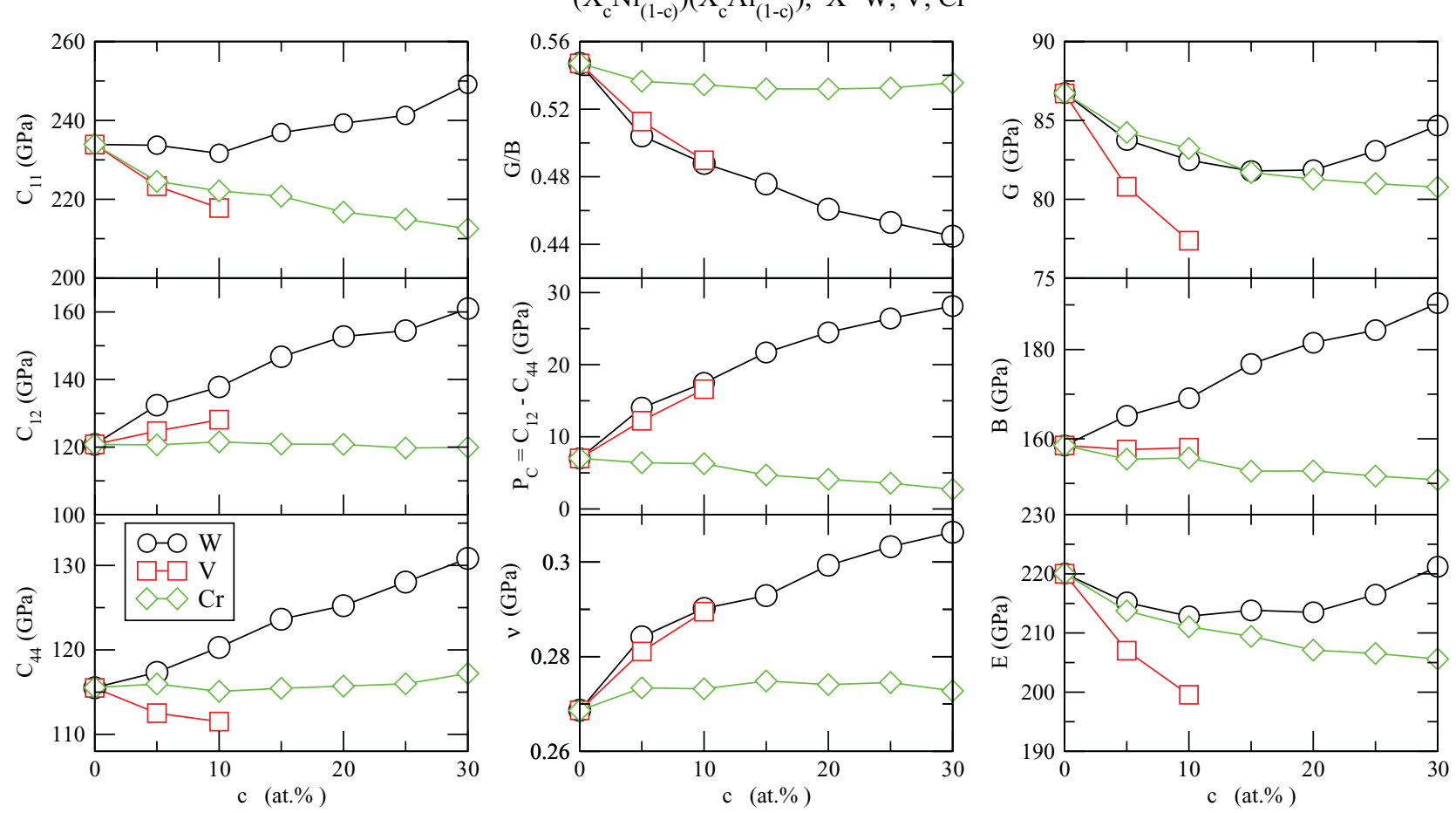

FIG. 6. (Color online) Calculated elastic constants $C_{11}, C_{12}$, and $C_{44}$, Pugh ratio $G / B$, Cauchy pressure $P_{C}=\left(C_{12}-C_{44}\right)$, Poisson ratio $v$, shear moduli $G$, bulk moduli $B$, and Young moduli $E$ of NiAl-X alloys with $\mathrm{X}=\mathrm{W}, \mathrm{V}$, and $\mathrm{Cr}$ located on both the $\mathrm{Ni}$ and the $\mathrm{Al}$ sublattices. 
sublattices) has a weak effect on the brittle vs ductile behavior in $B 2 \mathrm{NiAl}$ alloys.

\section{ACKNOWLEDGMENTS}

Financial support from the Russian Foundation for Basic Research (Grant No. 10-02-00-194a), the Swedish Research Council grant 621-2011-4426 and the Swedish Foundation for Strategic Research grant SRL 10-0026 are acknowledged. This study was supported in part by the Ministry of Education and Science of the Russian Federation within the framework of the program "Basic and applied research and experimental development carried out within the state task by subordinated higher educational institutions." Calculations were performed at the Joint Supercomputer Center of the Russian Academy of Sciences (Moscow) and the Swedish National Infrastructure for Computing (SNIC) National Supercomputer Centre (NSC) in Linköping, Sweden.

\section{APPENDIX}

In the figures in this Appendix we plot the calculated elastic constants $C_{11}, C_{12}$, and $C_{44}$, Pugh ratio $G / B$, Cauchy pressure $P_{C}=\left(C_{12}-C_{44}\right)$, Poisson ratio $v$, shear moduli $G$, bulk moduli $B$, and Young moduli $E$ of NiAl-X alloys with $\mathrm{X}=\mathrm{Co}$ and Re located on the Ni sublattice (Fig. 4), Sc and Ti located on the Al sublattice (Fig. 5), and W, V, and Cr located on both the Ni and the Al sublattices (Fig. 6). *alenaponomareva@yahoo.com

${ }^{1}$ T. B. Massalski, J. L. Murray, L. H. Bennett, and H. Baker, Binary Alloy Phase Diagrams (American Society for Metals, Metals Park, $\mathrm{OH}, 1986)$

${ }^{2}$ I. Baker and P. R. Munroe, J. Met. 40, 28 (1988).

${ }^{3}$ K. Ishida, R. Kainuma, N. Ueno, and T. Nishizawa, Metall. Mater. Trans. A 22, 441 (1991).

${ }^{4}$ G. Frommeyer, R. Rablbauer, and H. J. Schäfer, Intermetallics 18, 299 (2010).

${ }^{5}$ H. Li, J. Guo, H. Ye, Q. Wang, and J. C. He, Mater. Lett. 62, 61 (2008).

${ }^{6}$ C. Zhang, P. Han, J. Li, M. Chi, L. Yan, Y. Liu, X. Liu, and B. Xu, J. Phys. D 41, 095410 (2008).

${ }^{7}$ M. Balasubramanian, D. M. Pease, J. I. Budnick, T. Manzur, and D. L. Brewe, Phys. Rev. B 51, 8102 (1995); M. Daniel, M. Balasubramanian, D. L. Brewe, M. J. Mehl, D. M. Pease, and J. I. Budnick, ibid. 61, 6637 (2000).

${ }^{8}$ G. Frommeyer, R. Fischer, J. Deges, R. Rablbauer, and A. Schneider, Ultramicroscopy 101, 139 (2004).

${ }^{9}$ A. W. Wilson and J. M. Howe, Scripta Mater. 41, 327 (1999).

${ }^{10}$ R. Darolia, D. F. Lahrman, R. D. Field, and A. J. Freeman, Mater. Res. Soc. Symp. Proc. 133, 113 (1989).

${ }^{11}$ P. R. Munroe and I. J. Baker, Mater. Res. 7, 2119 (1992).

${ }^{12}$ R. D. Field, D. F. Lahrman, and R. Darolia, Acta Metall. Mater. 39, 2961 (1991).

${ }^{13}$ R. Fisher, G. Frommeyer, and A. Schneider, Mater. Sci. Eng. A 353, 87 (2003).

${ }^{14}$ Y. Terada, K. Ohkubo, T. Mohri, and T. Suzuku, Mater. Sci. Eng. A 329-331, 468 (2002).

${ }^{15}$ G. Bozzolo, R. D. Noebe, and F. Honecy, Intermetallics 8, 7 (2000).

${ }^{16}$ M. I. Medvedeva, Y. N. Gornostyrev, D. L. Novikov, O. N. Mryasov, and A. J. Freeman, Acta Mater. 46, 3433 (1998).

${ }^{17}$ K. Parlinski, P. T. Jochym, R. Kozubski, and P. Oramus, Intermetallic 11, 157 (2003).

${ }^{18}$ C. R. Kao, L. M. Pike, S.-L. Chen, and Y. A. Chang, Intermetallics 2, 235 (1994).

${ }^{19}$ H. Hosoda, K. Inoue, and Y. Mishima, Mater. Res. Soc. Symp. Proc. 364, 437 (1995).

${ }^{20}$ S. F. Pugh, Philos. Mag. Ser. 7 45, 823 (1954).

${ }^{21}$ D. Pettifor, Mater. Sci. Technol. 8, 345 (1992).
${ }^{22}$ L. Vitos, Computational Quantum Mechanics for Materials Engineers: The EMTO Method and Applications (Springer-Verlag, London, 2007).

${ }^{23}$ L. Vitos, I. A. Abrikosov, and B. Johansson, Phys. Rev. Lett. 87, 156401 (2001)

${ }^{24}$ J. Kollár, L. Vitos, and H. L. Skriver, in Electronic Structure and Physical Properties of Solids: The Uses of the LMTO Method, Lecture Notes in Physics, edited by H. Dreyssé (Springer- Verlag, Berlin, 2000), pp. 85-113.

${ }^{25}$ L. Vitos, P. A. Korzhavyi, and B. Johansson, Phys. Rev. Lett. 88, 155501 (2002)

${ }^{26}$ D. Music, T. Takahashi, L. Vitos, C. Asker, I. A. Abrikosov, and J. M. Schneider, Appl. Phys. Lett. 91, 191904 (2007).

${ }^{27}$ I. D. Bleskov, E. A. Smirnova, Yu. Kh. Vekilov, P. A. Korzhavyi, B. Johansson, M. Katsnelson, L. Vitos, I. A. Abrikosov, and E. I. Isaev, Appl. Phys. Lett. 94, 161901 (2009).

${ }^{28}$ C. Asker, L. Vitos, and I. A. Abrikosov, Phys. Rev. B 79, 214112 (2009).

${ }^{29}$ T. Gebhardt, D. Music, D. Kossmann, M. Ekholm, I. A. Abrikosov, L. Vitos, and J. M. Schneider, Acta Mater. 59, 3145 (2011).

${ }^{30}$ B. L. Györffy, A. J. Pindor, J. B. Staunton, G. M. Stocks, and H. Winter, J. Phys. F 15, 1337 (1985).

${ }^{31}$ J. P. Perdew and Y. Wang, Phys. Rev. B 45, 13244 (1992).

${ }^{32}$ Y. Wang and J. P. Perdew, Phys. Rev. B 44, 13298 (1991); J. P. Perdew, J. A. Chevary, S. H. Vosko, K. A. Jackson, M. R. Pederson, D. J. Singh, and C. Fiolhais, ibid. 46, 6671 (1992).

${ }^{33}$ A. V. Ruban and H. L. Skriver, Phys. Rev. B 66, 024201 (2002); A. V. Ruban, S. I. Simak, P. A. Korzhavyi, and H. L. Skriver, ibid. 66, 024202 (2002)

${ }^{34}$ I. A. Abrikosov, A. M. N. Niklasson, S. I. Simak, B. Johansson, A. V. Ruban, and H. L. Skriver, Phys. Rev. Lett. 76, 4203 (1996); I. A. Abrikosov, S. I. Simak, B. Johansson, A. V. Ruban, and H. L. Skriver, Phys. Rev. B 56, 9319 (1997).

${ }^{35} \mathrm{G}$. Grimvall, Thermophysical Properties of Materials, 1st ed. (Elsevier, Amsterdam, 1999).

${ }^{36}$ M. J. Mehl, J. E. Osburn, D. A. Papaconstantopoulos, and B. M. Klein, Phys. Rev. B 41, 10311 (1990).

${ }^{37}$ E. G. Brovman and Yu. M. Kagan, Sov. Phys. Usp. 17, 125 (1974).

${ }^{38} \mathrm{C}$. Zener, Elasticity and Anelasticity of Metals (University of Chicago, Chicago, 1948). 
${ }^{39}$ A. V. Ruban and H. L. Skriver, Phys. Rev. B 55, 856 (1997).

${ }^{40}$ P. A. Korzhavyi, A. V. Ruban, A. Y. Lozovoi, Yu. Kh. Vekilov, I. A. Abrikosov, and B. Johansson, Phys. Rev. B 61, 6003 (2000); A. Alavi, A. Y. Lozovoi, and M. W. Finnis, Phys. Rev. Lett. 83, 979 (1999).

${ }^{41}$ A. Y. Lozovoi and Y. Mishin, Phys. Rev. B 68, 184113 (2003).

${ }^{42}$ A. Taylor and N. J. Doyle, J. Appl. Cryst. 5, 201 (1972); E. T. Henig and H. L. Lukas, Z. Metallkd. 66, 98 (1975).

${ }^{43}$ C. Jiang, Acta Mater. 55, 4799 (2007).

${ }^{44}$ G. Kresse and J. Furthmuller, Phys. Rev. B 54, 11169 (1996).

${ }^{45}$ G. Kresse and J. Furthmuller, Comput. Mater. Sci. 6, 15 (1996).

${ }^{46} \mathrm{M}$. Mehl, B. Klein, and D. Papaconstantopoulos, in Intermetallic Compounds, Vol. 1, edited by J. Westbrook and R. Fleischer (Wiley, London, 1995), p. 19.

${ }^{47}$ D. J. Singh, Phys. Rev. B 46, 14392 (1992).

${ }^{48}$ C. Zhang, P. Han, J. Li, M. Chi, L. Yan, Y. Liu, X. Liu, and B. Xu, J. Phys. D 41, 095410 (2008).

${ }^{49}$ X. Huang, I. I. Naumov, and K. M. Rabe, Phys. Rev. B 70, 064301 (2004).

${ }^{50}$ Y. Wang, J. J. Wang, H. Zhang, V. R. Manga, S. L. Shang, L.-Q. Chen, and Z.-K. Liu, J. Phys. Condens. Matter 22, 225404 (2010).
${ }^{51}$ T. Li, J. W. Morris Jr., and D. C. Chrzan, Phys. Rev. B 70, 054107 (2004).

${ }^{52}$ P. Lazar and R. Podloucky, Phys. Rev. B 73, 104114 (2006).

${ }^{53}$ M. Mostoller, R. M. Nicklow, D. M. Zehner, S.-C. Lui, J. M. Mundenar, and E. W. Plummer, Phys. Rev. B 40, 2856 (1989).

${ }^{54}$ G. Simmons and H. Wang, Single Crystal Elastic Constants and Calculated Aggregate Properties: A Handbook (MIT Press, Cambridge, MA, 1971).

${ }^{55}$ N. Rusovicánd and H. Warlimont, Phys. Status Solidi A 44, 609 (1977).

${ }^{56}$ T. Davenport, L. Zhou, and J. Trivisonno, Phys. Rev. B 59, 3421 (1999).

${ }^{57}$ D. G. Sangiovanni, V. Chirita, and L. Hultman, Phys. Rev. B 81, 104107 (2010)

${ }^{58} \mathrm{P}$. Villas and L. Calvert, Pearson's Handbook of Crystallographic Data for Intermetallic Phases, 2nd ed. (ASM International, Materials Park, OH, 1991).

${ }^{59} \mathrm{P}$. Mohn, Magnetism in the Solid State. An Introduction (SpringerVerlag, Berlin, 2003).

${ }^{60}$ P. Mohn, C. Persson, P. Blaha, K. Schwarz, P. Novák, and H. Eschrig, Phys. Rev. Lett. 87, 196401 (2001). 